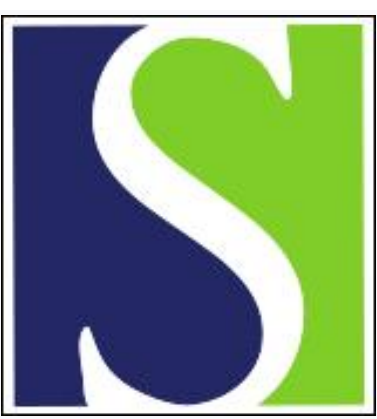

Scand J Work Environ Health 2010;36(6):484-487

https://doi.org/10.5271/sjweh.3082

Published online: 25 Aug 2010, Issue date: Nov 2010

Searching for high-quality articles about intervention studies in occupational health - what is really missed when using only the Medline database?

by Rollin L, Darmoni S, Caillard J-F, Gehanno J-F

Affiliation: Service de Médecine du Travail, Rouen University Hospital, 1 rue de Germont, 76000 Rouen, France. laetitia.rollin@chu-rouen.fr

Refers to the following text of the Journal: 2009;35(6):461-465

The following article refers to this text: 2018;44(6):670-677

Key terms: article; bibliometrics; database; intervention study; Medline; occupational health

This article in PubMed: www.ncbi.nlm.nih.gov/pubmed/20740265 


\title{
Searching for high-quality articles about intervention studies in occupational health - what is really missed when using only the Medline database?
}

\author{
by Laetitia Rollin, MD, ${ }^{1,2}$ Stefan Darmoni, MD, PhD, ${ }^{2}$ Jean-François Caillard, MD, PhD, ${ }^{2}$ Jean-François \\ Gehanno, $M D, P h D^{1,2}$
}

\begin{abstract}
Rollin L, Darmoni S, Caillard J-F, Gehanno J-F. Searching for high-quality articles about intervention studies in occupational health - what is really missed when using only the Medline database? Scand J Work Environ Health. 2010;36(6):484-487.
\end{abstract}

Objective Most occupational health physicians access electronic databases to obtain reliable medical information. Although it has been demonstrated that the use of Medline alone does not ensure comprehensiveness, many experts rely solely on this database. Our study aimed to discover to what extent the physician who limits his/her search to Medline misses studies of high quality.

Methods We constructed a "gold standard" database of high-quality intervention studies gathering all the references included in the systematic reviews of the Cochrane Library and indexed under the topic "occupational health field". We then searched all these references, one by one, in Medline.

Results Overall, $88.8 \%$ [ $95 \%$ confidence interval $(95 \%$ CI $) 86.1-91.5]$ of the high quality studies included in our gold standard database were indexed in Medline. References included in reviews on psychiatric or psychological topics were significantly less often indexed in Medline [81.7\% (95\% CI 75.9-88.5)] than references included in reviews on other topics [92.2\% (95\% CI 89.5-95.0)] ( $\mathrm{P}=0.001)$.

Conclusion The recall ratio of Medline for high-quality intervention studies is close to $90 \%$. For occupational health practitioners who aim to find reliable answers to their daily practice questions, searching Medline only is more cost-effective than previously thought.

Key terms bibliometrics.

Many electronic databases are available to find reliable medical information, but none of these databases are comprehensive: for example, some articles are referenced in one unique database (1) and others are only referenced in a few databases (2-5). These findings were also observed in occupational medicine and toxicology $(6,7)$. As a result, researchers are recommended to search multiple databases when performing comprehensive articles research, an approach that is standard practice for conducting meta-analysis. Nevertheless, more hits do not necessarily mean higher quality studies.

The aim of meta-analysis is to find all studies about one subject. Although physicians have different objectives, they face the same constraint: they need to identify, in a limited amount of time, essential and highquality studies. Yet, while it has been demonstrated that the use of Medline alone does not allow for comprehensiveness, it is not known to what extent the physician who limits his/her search to Medline really misses many studies of high quality. Therefore, we performed a study to assess the performance of Medline in retrieving specifically high-quality intervention studies in the field of occupational health.

\section{Method}

We included all the systematic reviews of the Cochrane Library indexed under the topic "occupational health field" in December 2009. Exclusion criteria were the following: (i) withdrawn systematic reviews, (ii) reviews

1 Institute of Occupational Health, Rouen University Hospital and University of Rouen, France.

2 Computer and Networks Department LITIS EA 4108, Rouen University Hospital, France.

Correspondence to: Dr L Rollin, Service de Médecine du Travail, Rouen University Hospital, 1 rue de Germont, 76000 Rouen, France. [E-mail: laetitia.rollin@chu-rouen.fr] 
using $<2$ bibliographic databases, and those restricted to English-language studies.

All references included in each review were identified from the section "References to studies included in this review". A "gold standard" database was built by gathering all these cited studies, excluding grey literature, books, abstracts, and personal communications.

Each individual reference was searched in Medline using the fields "publication date", "volume" and "first page". When no result was identified, we searched with the name of the first author, the main title words, or by scanning the full year of the journal. This allowed us to determine the percentage of studies indexed in Medline. To assess the medical specialties concerned by each review, we used a Medline categorization algorithm that we had developed previously. (8) Three categories were found to have sufficient frequency in each class: psychiatric and psychological topics, rheumatology, and others. The recall ratio for each of these topics was calculated and Fisher's exact test was used to test if the recall ratio significantly differ at the $\alpha$ risk of 5\%. Statistical analyses were performed using the STATA software program, version 9.0 (StataCorp, College Station, TX USA).

\section{Results}

We included 42 reviews indexed under the topic "occupational health field", all used $\geq 2$ independent reviewers and relied on $\geq 2$ bibliographic databases to identify potentially relevant studies; none of them restricted the search to English-language articles. Of these 42 reviews, 40 had $\geq 1$ study in the section "References to studies included in this review". Each of them included a mean of 13.8 references; the maximum number of studies included in a review was 61 . Overall, 552 references were identified, among which 8 concerned only an abstract, 7 made reference to grey literature or books, and 1 made reference to a personal communication. These 16 references were excluded from our analysis. As a result, our gold standard database included 536 articles. Of these, 476 [88.8\% (95\% CI 86.1-91.5)] were indexed in Medline and 60 [11.2\% (95\% CI 8.5-13.9)] were not. The detailed results are presented in table 1 .

For references included in reviews concerning psychiatric and psychological topics, the Pearson $\chi^{2}$ test showed a significant link between the topic of the review and the rate of studies indexed in Medline. Psychiatric and psychological topics were less often indexed in Medline [81.7\% (95\% CI 75.9-88.5)] than references provided by reviews on rheumatology $[91.0 \%$ (95\% CI 87.1-94.9)] or other topics [92.2\% (95\% CI 89.5-95.0)] $(\mathrm{P}=0.001)$.

\section{Discussion}

The main result of our study is that, when considering only high quality studies in occupational health, the use of Medline alone provides a very satisfying recall, close to $90 \%$.

Most of the studies performed so far (13-16) evaluated the precision and recall of Medline for all the available literature in a specific field. Since more is not necessarily better, we took a different approach and built a gold standard database, including only studies on occupational health of high methodological quality. The challenge was to identify such articles and to that end we relied on the works of experts from the Cochrane Collaboration. The reviews produced within the Cochrane Collaboration are prepared following strict and standardized methods concerning information retrieval and assessment of methodological quality, which allows at the same time comprehensiveness and restriction to high-quality publications on a subject $(9,10)$.

Abstracts presented in congress or meetings that were already included in the Cochrane systematic review were excluded from our gold standard database since it has been clearly demonstrated such abstracts often display invalid results $(11,12)$. Therefore, we can assume that our database really included all the high quality studies relevant to the topics covered by the systematic reviews and only high-quality studies. However, since our study concerned only Cochrane systematic reviews, our gold standard database included only intervention studies, which may not represent all high-quality studies available in occupational health.

It has been demonstrated in many studies concerning various specialties, including occupational medicine, that the recall ratio of Medline was far from $100 \%$ $(1,6,13-16)$.

Nevertheless, none of these studies restricted their research to papers of high quality; the recall ratios published concern, therefore, a considerable amount of literature, part of it being probably of low relevance or quality.

Our results confirm that a comprehensive systematic review cannot rely on Medline only, even if it has been demonstrated that the use of Embase in addition to Medline to perform meta-analysis influenced the pooled estimate by an average of only $6 \%$ [ratio of odds ratio of 0.94 (95\% CI 0.88-0.99)] (17). Nevertheless, searching multiple databases is complicated, costly, timeconsuming, and often yields the recovery of irrelevant trials or redundant data. Even if researchers can afford this, clinicians cannot as they need quick and reliable answers. Since we have demonstrated that $88.8 \%$ (95\% CI 86.1-91.5) of high-quality intervention studies could be retrieved by a Medline search, our study provides 
Table 1. List of Cochrane reviews used to build the gold standard database of high quality studies. Number of articles referenced in each one, selected for the database, and finally retrieved by the Medline search.

\begin{tabular}{|c|c|c|c|}
\hline Title of the Cochrane review & $\begin{array}{c}\text { Number of } \\
\text { references } \\
\text { in the } \\
\text { review }\end{array}$ & $\begin{array}{l}\text { Number of articles } \\
\text { included in the gold } \\
\text { standard database of } \\
\text { high quality studies a }\end{array}$ & $\begin{array}{c}\text { Number of } \\
\text { articles } \\
\text { retrieved by } \\
\text { Medline }\end{array}$ \\
\hline Alcohol and drug screening of occupational drivers for preventing injury & 3 & 3 & 2 \\
\hline Cognitive behavioral therapy for tinnitus & 6 & 6 & 6 \\
\hline Competitions and incentives for smoking cessation & 17 & 17 & 15 \\
\hline Back schools for non-specific low-back pain & 19 & 19 & 16 \\
\hline Exercise therapy for treatment of non-specific low-back pain & 61 & 61 & 57 \\
\hline Exercises for mechanical neck disorders & 31 & 31 & 30 \\
\hline Insoles for prevention and treatment of back pain & 6 & 6 & 6 \\
\hline Interventions for preventing injuries in the agricultural industry & 8 & 7 & 6 \\
\hline Interventions for preventing injuries in the construction industry & 5 & 5 & 4 \\
\hline Alkalinization for organophosphorus pesticide poisoning & 1 & 0 & 0 \\
\hline Antibiotic prophylaxis for leptospirosis & 3 & 3 & 3 \\
\hline Antibiotics for leptospirosis & 3 & 3 & 3 \\
\hline Antiretroviral post-exposure prophylaxis for occupational HIV exposure & 9 & 8 & 8 \\
\hline Drugs for preventing lung cancer in healthy people & 4 & 4 & 4 \\
\hline $\begin{array}{l}\text { Effectiveness of vocational rehabilitation intervention on the return to work } \\
\text { and employment of persons with multiple sclerosis }\end{array}$ & 2 & 2 & 0 \\
\hline Influenza vaccination for healthcare workers who work with the elderly & 3 & 3 & 3 \\
\hline Interventions for preventing voice disorders in adults & 2 & 2 & 2 \\
\hline Interventions for treating functional dysphonia in adults & 6 & 6 & 5 \\
\hline Interventions to improve occupational health in depressed people & 11 & 11 & 11 \\
\hline Interventions to prevent occupational noise induced hearing loss & 21 & 21 & 20 \\
\hline Interventions to promote the wearing of hearing protection & 7 & 7 & 7 \\
\hline Lumbar supports for prevention and treatment of low back pain & 15 & 14 & 11 \\
\hline $\begin{array}{l}\text { Manual material handling advice and assistive devices for preventing } \\
\text { and treating back pain in workers }\end{array}$ & 11 & 11 & 9 \\
\hline Medicinal and injection therapies for mechanical neck disorders & 37 & 37 & 30 \\
\hline Melatonin for the prevention and treatment of jet lag & 10 & 8 & 7 \\
\hline $\begin{array}{l}\text { Multidisciplinary biopsychosocial rehabilitation for neck and shoulder } \\
\text { pain among working age adults }\end{array}$ & 2 & 2 & 2 \\
\hline $\begin{array}{l}\text { Multidisciplinary biopsychosocial rehabilitation for subacute low-back } \\
\text { pain among working age adults }\end{array}$ & 2 & 2 & 2 \\
\hline $\begin{array}{l}\text { Multidisciplinary rehabilitation for fibromyalgia and musculoskeletal } \\
\text { pain in working age adults }\end{array}$ & 9 & 9 & 9 \\
\hline $\begin{array}{l}\text { Non-surgical treatment (other than steroid injection) for } \\
\text { carpal tunnel syndrome }\end{array}$ & 21 & 21 & 18 \\
\hline $\begin{array}{l}\text { Physical conditioning programs for improving work outcomes in workers } \\
\text { with back pain }\end{array}$ & 20 & 18 & 17 \\
\hline Preventing occupational stress in healthcare workers & 19 & 19 & 12 \\
\hline Psychological debriefing for preventing post traumatic stress disorder & 15 & 11 & 11 \\
\hline $\begin{array}{l}\text { Psychosocial interventions for prevention of psychological disorders in } \\
\text { law enforcement officers }\end{array}$ & 10 & 10 & 3 \\
\hline Screening for lung cancer & 7 & 7 & 7 \\
\hline Surgical treatment options for carpal tunnel syndrome & 36 & 34 & 31 \\
\hline Surgical versus non-surgical treatment for carpal tunnel syndrome & 4 & 4 & 4 \\
\hline Vaccines for preventing hepatitis B in health-care workers & 21 & 21 & 21 \\
\hline Vocational rehabilitation for people with severe mental illness & 18 & 17 & 12 \\
\hline $\begin{array}{l}\text { Work conditioning, work hardening and functional restoration for } \\
\text { workers with back and neck pain }\end{array}$ & 20 & 20 & 19 \\
\hline Workplace interventions for smoking cessation & 47 & 46 & 43 \\
\hline Total & 552 & 536 & $476^{b}$ \\
\hline
\end{tabular}

a Some articles referenced in the Cochrane review were not included in our database of high quality intervention studies because they were abstracts, grey literature or personal communication. This explains the difference of numbers in the column "references in the review" and the column "references included in the database".

b $88.8 \%$. 
optimistic results for the practitioner: although Medline is not exhaustive for the whole literature nor the sole repository for high quality intervention studies, it can be used with a very limited loss of reliable data with one exception. For psychiatric and psychological topics [recall ratio of $81.7 \%$ (95\% CI 75.9-88.5)] topics, it would be advisable for the user to add a specific database, such as PsycINFO. This confirms the finding of McDonald who demonstrated that Medline indexes only $47 \%$ of psychiatry journals (3).

Finally, authors of the Cochrane reviews use highly complex search strategies to identify articles relevant to their specific research question. Since the recall of a search in a database is dependant on the skills of the user, demonstrating that nearly $90 \%$ of good quality studies are indexed in Medline does not systematically mean that every user will be able to identify them (18). Therefore, the end-user should be properly trained on information retrieval methods, in order to get as much benefit as possible from this database.

In conclusion, occupational health practitioners who aim to find answers in a limited amount of time for their daily practice and patient care can search only Medline since it allows them to retrieve nearly $90 \%$ of the essential publications.

\section{References}

1. Wilkins T, Gillies RA, Davies K. Embase versus Medline for family medicine searches: can Medline searches find the forest or a tree? Can Fam Physician. 2005;51:848-9.

2. Suarez-Almazor ME, Belseck E, Homik J, Dorgan M, RamosRemus C. Identifying clinical trials in the medical literature with electronic databases: Medline alone is not enough. Control Clin Trials. 2000;21:476-87.

3. McDonald S, Taylor L, Adams C. Searching the right database: a comparison of four databases for psychiatry journals. Health Libr Rev. 1999;16:151-6.

4. Watson RJ, Richardson PH. Identifying randomized controlled trials of cognitive therapy for depression: comparing the efficiency of Embase, Medline and PsycINFO bibliographic databases. Br J Med Psychol. 1999;72:535-42.

5. Woods D, Trewheellar K. Medline and Embase complement each other in literature searches. BMJ. 1998;316:1166.
6. Gehanno JF, Paris C, Thirion B, Caillard JF. Assessment of bibliographic databases performance in information retrieval for occupational and environmental toxicology. Occup Environ Med. 1998;55:562-6.

7. Verbeek J, Salmi J, Pasternack I, Jauhiainen M, Laamanen I, Schaafsma F, et al. A search strategy for occupational health intervention studies. Occup Environ Med. 2005;62:682-7.

8. Darmoni SJ, Neveol A, Renard JM, Gehanno JF, Soualmia LF, Dahamna B, et al. A Medline categorization algorithm. BMC Med Inform Decis Mak. 2006;6:7.

9. Bero L, Rennie D. The Cochrane Collaboration: preparing, maintaining, and disseminating reviews of the effects of health care. JAMA.1995;274:1935-8.

10. Jadad AR, Haynes RB. The Cochrane Collaboration: advances and challenges in improving evidence-based decision making. Med Decis Making. 1998;279:611-4.

11. Scherer RW, Langenberg P, von Elm E. Full publication of results initially presented in abstracts. Cochrane Database Syst Rev. 2007;2:MR000005.

12. Rollin L, Darmoni S, Caillard JF, Gehanno JF. Fate of abstracts presented at the ICOH International Meeting: are they followed by publication in peer-reviewed journals. Scand J Work Environ Health. 2009;35(6):461-5.

13. Brettle AJ, Long AF. Comparison of bibliographic databases for information on the rehabilitation of people with severe mental illness. Bull Med Libr Assoc. 2001;89:353-62.

14. Betrán AP, Say L, Gülmezoglu AM, Allen T, Hampson L. Effectiveness of different databases in identifying studies for systematic reviews: experience from the WHO systematic review of maternal morbidity and mortality. BMC Med Res Methodol. 2005;28;5:6.

15. Lemeshow AR, Blum RE, Berlin JA, Stoto MA, Colditz GA. Searching one or two databases was insufficient for meta-analysis of observational studies. J Clin Epidemiol. $2005 ; 58: 867-73$.

16. Royle P, Bain L, Waugh N. Systematic reviews of epidemiology in diabetes: finding the evidence. BMC Med Res Methodol. 2005;8;5:2.

17. Sampson M, Barrowman NJ, Moher D, Klassen TP, Pham B, Platt R, et al. Should meta-analysts search Embase in addition to Medline? J Clin Epidemiol. 2003;56:943-55.

18. Watson RJ, Richardson PH. Identifying randomized controlled trials of cognitive therapy for depression: comparing the efficiency of Embase, Medline and PsycINFO bibliographic databases. Br J Med Psychol. 1999;72:535-42.

Received for publication: 3 May 2010 